\title{
Propostas de educação popular em Campinas: "As aulas noturnas"
}

\section{Mauricéia Ananias*}

\begin{abstract}
RESUMO: Utilizando-se da pesquisa realizada em escritos da época, década de 1870, como jornais e almanaques, e da documentação encontrada sobre a fundação das "aulas noturnas", mantidas pela Sociedade Propagadora de Instrução, em Campinas, pretende-se conceituar a educação oferecida por essa escola como além do objetivo primeiro de toda e qualquer educação elementar, a alfabetização. Nela, esperava-se que as crianças e os adultos, ao se formarem, fossem inseridos em uma nova sociedade que se acreditava em formação. Assim, o artigo busca encontrar na educação a formação de homem, mundo e sociedade que a elite cafeicultora propunha para essa camada pobre presente no então espaço urbano nascente.
\end{abstract}

Palavras-chave: Aulas noturnas, Campinas, educação popular, escolas, maçonaria

As ferrovias, a imigração, o uso de técnicas agrícolas avançadas, a imprensa escrita, a incipiente industrialização, a utilização do telefone, da iluminação a gás, as primeiras experiências com a luz elétrica, a constituição de um mercado de trabalho livre, a construção de grandes casas e palacetes, as atividades artísticas e recreativas expressavam as transformações sofridas pela cidade que reconfigurava o seu perfil rural. Nesse momento, essas mudanças significavam a urbanização e a modernização da antiga Vila de São Carlos, Campinas, que agora ganhava ares de metrópole.

Convivendo com essa cidade, que ostentava riqueza e poder, existia outra, suja e esburacada, onde muitas vezes o guiar de um ou muitos escravos

\footnotetext{
* Mestre em História da Educação pela Faculdade de Educação da Universidade Estadual de Campinas (Unicamp). E-mail:romau@bol.com.br
} 
não era suficiente para livrar o seu senhor ou senhora de ter os pés atolados numa poça d'água, ou os sapatos sujos por resíduos deixados por inúmeros animais que dividiam o espaço com os transeuntes.

\footnotetext{
Esta cidade de que vos falo não é tão visível, a sua existência é furtiva, pois é incômoda à outra. É produzida a cada dia, sobretudo pelos escravos e pelos pobres. As fontes deixam apenas que se possa entrevê-la. Não se mostra, pois é proibida, mas existe e pulsa escondida, reprimida, pusilânime ou desafiadora. Essa cidade clandestina, despudorada e transgressora das posturas é que nos convém visitar (...). Os seus cortiços e pardieiros, os seus becos e ruazinhas malcheirosas (...). (Lapa 1996, p. 124)
}

E foi nessa cidade marcada por transformações, desigualdades e contradições, onde grupos e realidades distintas conviveram, que as escolas para os pobres foram construídas.

A defesa de suas construções e usos, pelos cafeicultores e pessoas a eles relacionadas, passa a compor o discurso da época. Defendiam, numa falsa idéia de igualdade, que ela deveria ser para todos, inclusive para os escravos, os imigrantes e migrantes, os libertos e os trabalhadores nacionais livres - e os seus filhos - que nada ou quase nada possuíam, além da sua força de trabalho.

Assim, algumas escolas menores foram construídas para essas pessoas, em especial a mantida pela Sociedade Promotora de Instrução, que defendia que o desenvolvimento e a prosperidade só aconteceriam se a sociedade garantisse a educação para todos.

Nesse espaço, e talvez em função dele, a proliferação das idéias vindas da Europa e dos Estados Unidos ganhou uma repercussão muito rápida entre os membros da elite cafeicultora. Considerados superiores, em decorrência dessas mesmas idéias, os "estrangeiros" poderiam com muito mais facilidades do que eles, apesar do já reconhecido crescimento intelectual, dar respostas e soluções para os também reconhecidos problemas brasileiros.

Fazer uma síntese dessas idéias e, o que é mais importante, demonstrálas não a partir da perspectiva do transplante cultural, mas sim de como essas mesmas idéias foram até mesmo "reinventadas", tendo como pressuposto a realidade brasileira e as suas contradições, não é tarefa fácil, senão impossível. 
A dificuldade não está apenas em resgatar as contribuições intelectuais do final do século XIX, extensas e de diversas interpretações, mas também em conseguir compreender, com todas as diferenças de entendimento, como essas idéias contribuíram nas transformações ocorridas nesse período em Campinas e no país e, principalmente, como e por que estiveram presentes nos debates acerca dos problemas educacionais.

Assim, optamos por resgatar alguns comentários - com a perspectiva de demonstrar dessa forma as idéias, que vindo de fora, construíram o debate teórico da época - dos homens que, reconhecidos socialmente, expunham seus argumentos comentando os diversos temas nos espaços que a imprensa Ihes oferecia.

Membros das elites campineiras tinham uma vida pública marcada pela atuação tanto política como econômica. Mesmo possuindo algumas vezes posições sociais e opiniões diferenciadas, convergiam quando a causa era a necessidade do desenvolvimento social e da educação. Como espaço privilegiado desses debates, escolhemos os almanaques e alguns artigos de jornais que circulavam pela cidade. ${ }^{1}$

Nomes como Francisco Quirino dos Santos, Francisco Glicério e José Maria Lisboa repetiam-se exaustivamente nos jornais e almanaques da época, citados como capitalistas, cafeicultores, profissionais liberais e membros de várias entidades, tanto agrícolas como financeiras.

Além disso, todos eles se envolveram direta ou indiretamente com construções e manutenções de escolas. Francisco Quirino dos Santos, Francisco Glicério e José Maria Lisboa compuseram a diretoria da Sociedade Propagadora de Instrução.

Esses mesmos homens que defenderam, construíram e mantiveram as escolas destinadas à população pobre em Campinas refletiam e, segundo o nosso entendimento, representavam o momento de transição pelo qual passava a cidade.

Na maioria, os mesmos fazendeiros e, principalmente, os seus filhos eram advogados, jornalistas, professores e escritores. Essas "múltiplas funções" expressavam a perspectiva da aliança entre os grandes proprietários rurais e a classe média urbana, com o intuito da construção de um outro modelo político para a sociedade.

O título de bacharel em direito enobrecia a aristocracia rural, dando-lhe um ar de modernidade e inteligência. Sua condição de detentora dos meios 
de produção recebia o embasamento científico racional a partir dessa formação acadêmica.

A diretoria da Sociedade Promotora de Instrução, que manteve as "aulas noturnas" da Loja Independência, teve em seus quadros representantes dessas elites.

Seu presidente, Francisco Quirino dos Santos, filho de um fazendeiro da região, formado pela Academia de Direito de São Paulo, mantinha um jornal na cidade. Além dessas atividades, foi um militante convicto do Partido Republicano local, atuando em diversas esferas da sociedade. Participou de várias associações e ocupou diversos cargos públicos, tais como o de vereador e de juiz de paz da cidade. Tinha como integrantes dessa mesma associação que presidia - Promotora de Instrução - nomes tão ou até mais reconhecidos do que o dele. ${ }^{2}$

Francisco Glicério e José Maria Lisboa também faziam parte da diretoria da Promotora. O primeiro, de origem não tão nobre quanto Quirino dos Santos, galgou o mesmo percurso deste. Mesmo não tendo o título de bacharel em direito, exerceu a advocacia na cidade. Atuava politicamente, sendo membro do Partido Republicano Paulista, tendo sido, inclusive, um dos organizadores da convenção de Itu e vereador em Campinas por esse mesmo partido. ${ }^{3} \mathrm{O}$ último, ligado à imprensa campineira, era gerente de $A$ Gazeta e foi editor dos almanaques (para os anos de 1871, 1872,1873) de Campinas.

Esses homens representavam, por suas idéias e atitudes, com bastante legitimidade, esse processo entendido como precursor da modernidade no país, demonstrada nesse trabalho como o conjunto das mudanças sofridas pela sociedade, que tinha como fundamento último a defesa de que "as coisas da cidade" deveriam ser regidas a partir dos pressupostos da razão e da ciência (Lapa 1996).

Mesmo reconhecendo as possíveis diferenças entre as idéias defendidas e as posições sociais desse grupo, procuraremos trabalhar com o referencial maior que os unia: o ideal de transformar o Brasil em uma civilização, tendo, entre outros elementos, a educação como um dos pilares dessa construção.

Partindo do pressuposto da prosperidade econômica, esse grupo acreditava que a riqueza material culminaria no desenvolvimento intelectual da humanidade. 
O discurso defendido por esses homens, encontrado nos almanaques da época, mostrou-se influenciado pelas idéias - o liberalismo, o positivismo e o evolucionismo - que marcaram o final do século XIX. Conhecedores desses ideais, acreditavam que a prosperidade econômica culminaria na elevação da sociedade, colocando-a no mesmo patamar daquelas que eles consideravam modelos.

Assim, apresentavam uma defesa, muitas vezes apaixonada, do progresso como uma necessidade para o país transformar-se em uma civilização.

Isso só aconteceria a partir do desenvolvimento material e intelectual do Brasil. Para tanto, a riqueza natural e o esforço individual que garantiria o desenvolvimento social eram vistos como imprescindíveis para realização de tal propósito. Dentro desse quadro, a educação era vista como um dos pilares que sustentariam e fariam com que a população acompanhasse esse desenvolvimento.

Para eles, o progresso - e a conseqüente construção da civilização seria o resultado final de um processo que, segundo alguns, começaria com a riqueza natural.

Campos Salles, que ocupou a Presidência do país entre 1898 e 1902, era defensor dessa idéia. Escritor freqüente dos almanaques campineiros, para ele, a riqueza de uma nação dependia, em princípio, da riqueza de seu solo.

E debaixo deste ponto de vista a fertilidade do solo e a clemencia do clima, sendo os mais poderosos elementos da produção, tornam-se por isso mesmo os melhores e os mais apreciaveis agentes da civilização, porque nellas reside a riqueza natural, immensa e inexgotavel, como immensa e inexgotavel é a propria natureza. (Almanak de Campinas para 1873, 1872, p. 73)

A partir dessa riqueza natural, o homem teria mais facilidades para construir a sua riqueza material. Essas facilidades seriam completadas com a iniciativa individual que, como exemplo, estimularia o coletivo a agir em prol do "município". De posse da riqueza material, conseguida através da ação da natureza e do homem, este último teria tempo para se dedicar aos "trabalhos da razão".

Essa fórmula, à primeira vista tão simples e mecânica, segundo a visão desses homens, refletia, na perspectiva deles, a realidade da região. 
Vivendo o auge da produção cafeeira, que para eles era resultado da riqueza do solo e do esforço dos cafeicultores, o capital oriundo dela era aplicado tanto no campo como, apesar dos contrastes, na cidade.

A inauguração de uma olaria, a Sampaio Peixoto, foi anunciada e comentada, tanto nos jornais da cidade como nos da Província, como uma "corajosa dedicação e verdadeiro amor ao progresso de sua cidade" em referência a Sampaio Peixoto, seu proprietário (Almanak de Campinas para 1871,1870 , p. 110).

Francisco Quirino dos Santos, também escritor dos almanaques, num artigo em que descreve a história da fundação da cidade, coloca todo o processo, desde o nascimento do povoado até o período em que escreve 1871 -, como uma marcha do progresso rumo à civilização. Numa referência explícita à crença de que o desenvolvimento levaria à realização plena da humanidade, finalizou seu artigo conclamando todos para marcharem rumo à civilização: "Ahi está de topo a ingreme ladeira para a subida que nos chama à longa viagem da civilização. E nós ainda não temos vencido mais do que os taboleiros à raiz da fulgida montanha. Vamos!" (Almanak de Campinas para 1871, p. 74).

As máquinas para a lavoura, o trabalho livre, a imigração, as ferrovias, a construção de associações que envolviam desde um rink de patinação até a inauguração de hospitais e passeios públicos, ou seja, qualquer ação ou realização era usada para confirmar a tese de que se o progresso material não estava concluído, pelo menos caminhava a passos largos para tal.

Numa referência à Revolução Francesa - as luzes contra as trevas da ignorância - e aos Estados Unidos - exemplo de povo dedicado e empreendedor - esse discurso era marcado pela exaltação ao trabalho, essa defesa era sempre feita tendo como referencial a ação pioneira dos norteamericanos.

Campos Salles, em artigo publicado pelo Almanaque de Campinas, em que discorria sobre a colônia de imigrantes "Sete Quedas" existente na fazenda de mesmo nome em Campinas, posicionou-se favorável a essa experiência de colonização européia existente na cidade e defendeu, numa perspectiva mais ampla, a vinda desses trabalhadores para o Brasil. Sua analogia utilizava-se da idéia de que as transformações só seriam possíveis com a mudança de governo. Este trecho do artigo, de tão interessante, merece transcrição: 
Proclamada a independência da União Americana com quatro milhões de habitantes, apenas, hoje as estatisticas levam a cifra a cerca de quarenta milhões!

E com a população desenvolve-se a industria, cresce a riqueza e diffundem-se as luzes da instrucção.

Ao passo que no Brasil império... Não, não façamos o paralello. Poupemos a nós mesmos essa vergonha immensa.

Basta que saibam os nossos agricultores, que só há um remédio para conjurar a crise - liberdade completa, o governo do povo pelo povo. (Almanak de Campinas para 1872, 1871, p. 94)

Como se pode perceber, o artigo já anunciava, na medida em que colocava a instrução ao lado do desenvolvimento da indústria e de sua possível riqueza, a defesa da necessidade de um progresso intelectual que acompanhasse o progresso material da cidade.

Na perspectiva do intelectual, esse grupo via na educação aquela que "espalharia a instrução e levaria a luz a todas as almas"; aqui nos parece clara a referência à Revolução Francesa. Essa visão dava à educação uma função não só de instruir formalmente as pessoas mas também de formar o homem. A ela cabia preparar esse "novo homem" para atuar na "nova sociedade" que eles acreditavam estar construindo.

Baseando-se nessa alegação, foram abertas escolas destinadas à população pobre em várias cidades do estado de São Paulo; muitas, a exemplo das aulas noturnas, eram mantidas pela maçonaria. Campinas, considerada uma das mais importantes cidades da época, teve, entre outras, uma escola mantida pelos maçons, que era destinada à instrução gratuita de adultos e crianças maiores de 12 anos que fossem reconhecidamente pobres.

A seleção para o acesso às aulas era baseada em critérios rígidos não só para os alunos, mas também para os professores. Esses deveriam ser profissionais reconhecidos pela sociedade. Um dos itens que legitimavam esse reconhecimento era o exercício do magistério em colégios de renome da cidade.

Em relação aos alunos, para ter acesso às aulas deveriam comprovar uma ocupação profissional. Essa exigência demonstra a preocupação que havia em ensinar os já alocados no mercado de trabalho. Graças a ela foi-nos possível conhecer, ainda que de uma forma superficial, a posição social desses alunos. 
Moraes (1990, p. 43) afirmou:

Segundo A Gazeta, dos 214 alunos matriculados na escola noturna, eram "livres" 191 e escravos 23; solteiros 203 e casados 9; brasileiros 199 e estrangeiros 15 (...) 103 artistas e 32 empregados, assim distribuídos: 34 carpinteiros, 15 pedreiros, 14 marceneiros, 10 ferreiros, 6 pintores, 4 fundidores, 4 sapateiros, 3 fogueteiros, 2 seleiros, 2 funileiros, 2 colcheiros, 1 oleiro, 1 marmorista, 1 chapeleiro, 11 empregados, 3 caixeiros, 2 copeiros, etc.

A relação das profissões indica a existência de um trabalhador nacional, na maioria livre, apesar de haver também alunos escravos com profissões tipicamente urbanas. Era o homem comum - e pobre - que, naquele momento, mais do que antes, passava a fazer parte efetivamente da vida da cidade.

Essa clientela talvez justifique as disciplinas oferecidas pelo curso. Inicialmente, a partir da década de 1870, os almanaques indicavam que a escola ensinava os alunos a ler, escrever e contar. Em 1878, apareciam as disciplinas de primeiras letras, caligrafia, história, aritmética e português. A partir dessa data, segundo Moraes (1981), houve uma ampliação acrescentando gramática, geometria, geografia, história pátria e contabilidade. Além dessas, disciplinas como "direitos do homem" e desenho aplicado faziam parte do programa.

A análise desse currículo aponta-nos que ele continha três preocupações básicas. A primeira era com a alfabetização, na medida em que ensinava a ler, escrever e contar. As noções básicas garantidas pelo ensino das primeiras letras e de caligrafia preparavam os alunos para o conhecimento de gramática, história e geografia. Além dessa formação, considerada essencial, disciplinas como geometria, contabilidade e desenho aplicado completavam o currículo.

A segunda preocupação era com a perspectiva do encaminhamento profissional. As atividades urbanas, tais como o comércio e a então indústria nascente, necessitavam de profissionais capacitados. O conhecimento em contabilidade, desenho aplicado e geometria habilitava-os para atuar nesses ramos.

Por último, segundo análise da proposta curricular apresentada pela escola, havia uma acentuada preocupação em que os alunos "aprendessem" os direitos dos homens na sociedade. 
Essa disciplina completava a tríade, oferecendo aos alunos a educação cívica. Trabalhar só com os alunos já alocados profissionalmente e preparálos para a atuação em sociedade pareceu-nos ser uma tentativa de adequálos à nova realidade que se instaurava.

Essa preocupação com a atuação da população pobre na sociedade também pode ser percebida na proposta metodológica utilizada pela escola.

As "lições de coisas", em contraposição à proposta da monarquia considerada abstrata e metafísica, propunham o ensino a partir da realidade dos alunos. Baseadas nos pressupostos do cientificismo, defendiam que todo e qualquer conhecimento deveria ter como ponto de partida o concreto, as experiências dos alunos. A abstração, ou seja, a conceituação oriunda disso, também deveria ter utilidade prática, servindo à sociedade.

Assim, com essa educação baseada na realidade e a ela servindo, o progresso poderia ser consolidado. Somente por meio dela a sociedade poderia se constituir como uma civilização.

"Nem outro progresso é realmente possível sem a cooperação do ensino, esse elemento primordial da civilização, tal como a entende a sociedade destes tempos" (Almanach Popular de Campinas para 1879, 1878, p. 23).

Por meio da educação, o "povo" deveria saber se governar e fazer valer os seus direitos políticos. Todas as pessoas envolvidas com essas construções compartilhavam da crença de que a educação, se não salvaria, pelo menos melhoraria os homens.

Nesse sentido, a escola passou a ter uma importância vital para a sociedade. Assim, ela deveria ser para todos. A categoria povo aparecia genericamente referindo-se a toda população campineira. As escolas que estavam sendo construídas, tanto o "Culto à Ciência" como as escolas populares, eram "destinadas ao povo" .

Essa defesa da educação para o povo, ou, como muitas vezes também apareceu, da instrução popular, parecia indicar a existência de um único tipo de escola para todos. Uma escola onde todos receberiam a mesma instrução, independentemente de sua condição social ou racial.

Essa idéia vinha reforçar a tese de que a escola era equalizadora das diferenças sociais. Para eles, por meio da escola, tanto "o proletario como o rico será acessivel a todos os empregos sociaes". 
Vimos que esse discurso não se confirmava na prática, pois na verdade existiam dois tipos diferenciados de educação. Uma direcionada aos filhos das elites, e nesse caso o Colégio Culto à Ciência foi o modelo dessa proposta em Campinas, e outra voltada ao aprendizado da população pobre, oferecida pelas escolas menores e gratuitas.

Para essa última, o ensino primário era suficiente. Por isso, a necessidade de ele ser mais amplo e oferecer algumas perspectivas de encaminhamento ao trabalho e umavisão de mundo, pois seria o único estudo oferecido. Não encontramos nenhuma referência a escolas que garantiriam o ensino secundário aa essas pessoas. $O$ acesso ao ensino superior sequer foi cogitado.

Numa sociedade dividida em classes, notoriamente com a escravidão, a defesa de mudanças não deveria atingir a superação real das diferenças. $O$ propósito era mudar o regime político e construir uma igualdade apenas no campo jurídico.

A escola deveria servir a esses dois propósitos, tanto assim, conforme já demonstrado, que tinha em seus currículos, além das disciplinas consideradas científicas, as de cunho político que "ensinavam aos Homens os seus direitos políticos e jurídicos". Ela era considerada o espaço privilegiado, não para construir novas leis e normas, mas sim para transmitir conhecimentos e, nesse sentido, legitimar essas idéias.

A ela caberia coroar o tão defendido progresso, igualando, de acordo com o merecimento, os homens.

Assim, em uma região de solo fértil, com uma agricultura produtiva, desenvolvendo uma riqueza material aplicada em outros segmentos econômicos, com um "povo" instruído intelectualmente, por meio da escola, construir-se-ia a tão propagada - e esperada - civilização.

\section{Notas}

1. As referências dos almanaques e jornais consultados para a elaboração deste texto encontramse na bibliografia final.

2. Homenagem posthuma a Francisco Quirino dos Santos. 1887.

3. Witter 1982

4. Para maiores informações sobre os editores e os almanaques ver: Galzerani, 1998.

5. O Colégio Culto à Ciência foi criado e mantido, entre os anos de 1874 a 1882, por uma Associação de fazendeiros e demais membros das elites campineiras que, apesar de não 
visar nenhum tipo de lucro, cobrava mensalidade dos alunos. Segundo Moraes (1981), além das pensões semestrais, os mesmos deveriam pagar uma "jóia" (valor em dinheiro), os custos dos materiais de estudo e a lavagem de roupas no estabelecimento, no caso dos internos. De acordo com essa autora, essas despesas tornavam o "Culto à Ciência" um dos colégios mais caros da região. Após 1892, o Colégio foi doado ao Estado, tornando-se público.

\section{Proposed of popular education in Campinas: \\ "The night classes"}

ABSTRACT: Researching newspapers and almanacs of the decade of 1870, and documents about the foundation of the "night classes", maintained by the Sociedade Propagadora of Instruction, in Campinas, intended to characterize the education offered by that school as besides the first objective of all and any elementary education, the literacy. The objective of that school was to introduce children and adults in the new society that was formed. This article intends to point the moral formation that the elite of Campinas proposed for the poor man that lived in the city.

\section{Referências bibliográficias}

ALMANAK de Campinas para 1871. T. da Gazeta de Campinas. Campinas, 1870. ALMANAK de Campinas para 1872. T. da Gazeta de Campinas. Campinas, 1871 ALMANAK de Campinas1873. T. da Gazeta de Campinas. Campinas, 1872.

ALMANAK da Província de São Paulo para 1873. São Paulo: Imesp, 1872.

ALMANACH Litterario de São Paulo para 1876. T. da Província de SP. São Paulo, 1875.

ALMANACH Popular para 1878. T. da Gazeta de Campinas. Campinas, 1877. ALMANACH Popular de Campinaspara 1879. T. da Gazeta. Campinas, 1878.

BATISTONI FILHO, D. Campinas: Uma visão histórica. Campinas: Pontes, 1996.

COSTA, J.C. Contribuições à história das idéias no Brasil: (o desenvolvimento da filosofia e a evolução histórica nacional ). Rio de Janeiro: J. Olympio, 1956.

GALZERANI, M.C.B. "O almanaque, a locomotiva da cidade moderna: Campinas, décadas de 1870 e 1880". Tese de doutoramento. Campinas: Unicamp, 1998. 
GEBARA, A. "Campinas, 1869-1875: Republicanismo, imprensa e sociedade". Dissertação de mestrado. São Paulo: FFLCH/USP, 1975.

HOMENAGEM Posthuma a Francisco Quirino dos Santos. Apontamentos biographicos. T. A Vapor do "Correio de Campinas". Campinas, 1887, Editor J. Salles Pinto.

JORNAL A Gazeta de Campinas nos anos de 1870 a 1880. Campinas, T. de A Gazeta de Campinas.

LAPA, J.R.A. A cidade: Os cantos e os antros - Campinas 1850-1900. São Paulo: Edusp, 1996.

MONOGRAFIA Histórica do Município de Campinas. Rio de Janeiro: Serviço gráfico do Instituto Histórico e Estatístico, 1952.

MORAES, C.S.V. "O ideário republicano e a educação: O Colégio Culto à Ciência de Campinas (1860-1892)". Dissertação de mestrado. São Paulo: USP/FE, 1981.

"A socialização da força de trabalho: Instrução popular e qualificação profissional no estado de São Paulo 1873 a 1934". Tese de doutoramento. São Paulo: USP/FFLCH, 1990.

WITTER, J.S. (org.). Idéias políticas de Francisco Glicério. Brasília/Rio de Janeiro: Fundação Casa de Rui Barbosa/MEC, 1982. 